\title{
A OPINIÃO PÚBLICA NAS \\ DEMOCRACIAS ESPETACULARES \\ CONEXÕES (IM)PERTINENTES DA \\ GOVERNAMENTALIDADE BIOPOLÍTICA \\ DE FOUCAULT E OS DISPOSITIVOS \\ ACLAMATÓRIOS DA SOBERANIA EM \\ AGAMBEN*
}

\author{
Castor M.M. Bartolomé Ruiz** \\ https://orcid.org/0000-0002-6826-1560 \\ castorbartolome@terra.com.br
}

\begin{abstract}
RESUMO O presente ensaio apresenta uma análise crítica das atuais democracias que se esvaziaram do poder deliberativo do demos para se tornarem, cada vez mais, democracias espetaculares. Inicialmente, seguindo os estudos de Foucault, analisam-se as implicações da governamentalidade sobre a democracia, principalmente a partir da emergência da opinião pública como técnica da razão de Estado. Posteriormente, relacionam-se os estudos de Foucault com as teses de Agamben a respeito da burocracia e a hierarquia, a fim de compreendermos como estas pesquisas desembocam no conceito de democracias espetaculares defendido por Agamben.
\end{abstract}

Palavras-chave Governamentalidade, opinião pública, razão de Estado, democracias espetaculares, Foucault, Agamben. 
ABSTRACT This essay presents a critical analysis of the current democracies that have emptied themselves of the deliberative power of the demos to become, more and more, spectacular democracies. Initially, following Foucault's studies, we analyze the implications of governmentality on democracy, especially from the emergence of public opinion as a technique of reason of state. Later, Foucault's studies are related to Agamben's theses on bureaucracy and hierarchy, in order to understand how these researches lead to the concept of spectacular democracies defended by Agamben.

Keywords Governmentality, public opinion, reason of state, spectacular democracies, Foucault, Agamben.

\section{Introdução}

O objetivo deste ensaio é fazer uma análise crítica do esvaziamento deliberativo das atuais democracias e como esse esvaziamento está conduzindoas perigosamente para o oximoro de se tornarem novos instrumentos de controle social e autoritarismo camuflado. Contudo, queremos registrar que a crítica aqui delineada coloca-se nas antípodas conceituais e políticas da defesa de quaisquer tipos de autoritarismo ou de qualquer retorno às políticas das trevas que as ditaduras militares já semearam por toda a América Latina. O objetivo da crítica que aqui apresentamos não é invalidar a democracia como forma de governo, mas pensar em outras formas de democracia que a tornam mais efetiva, e nunca na volta ou apelo a novos Leviatãs como falsos salvadores de nenhuma pátria.

Neste trabalho, propomos retomar as pesquisas de M. Foucault sobre o conceito de governamentalidade biopolítica e relacioná-las com as pesquisas de G. Agamben a respeito das democracias espetaculares. Esta aproximação epistemológica opera com a hipótese de que os atuais dispositivos governamentais, hegemônicos nas diversas esferas, produzem técnicas de administração das condutas dos indivíduos e, na maioria dos casos, esses dispositivos confrontam abertamente o sentido da autonomia e a capacitação para a autocracia dos sujeitos. Tencionamos mostrar como os dispositivos governamentais são responsáveis pelo esvaziamento de sentido das democracias modernas, tendo-as transformado, em grande parte, em democracias espetaculares.

Apresentaremos a nossa reflexão em três pontos. Num primeiro momento, analisaremos as pesquisas de Foucault sobre o início da governamentalidade moderna conferindo nelas o papel que a "opinião pública" teve na constituição 
da razão de Estado. Num segundo momento, faremos uma análise comparativa dos estudos da governamentalidade de Foucault com a genealogia da burocracia como tecnologia de governo em Agamben. Num terceiro momento, estudaremos os nexos dos estudos da governamentalidade de Foucault com as pesquisas de Agamben sobre as democracias espetaculares.

\section{A governamentalidade da opinião pública na razão de Estado}

Um primeiro ponto crítico de nossa análise consiste em diferenciar a democracia do liberalismo econômico. Embora haja uma constante tentativa de associar um como referente do outro, propomos mostrar que as contradições de um (liberalismo econômico) conduzem ao esvaziamento da outra (democracia). O liberalismo econômico é, essencialmente, um dispositivo de governamentalização das condutas (Gauthier, 1996, pp. 19-33). Como este dispositivo governamentalizador imbrica-se na efetivação do modelo das democracias modernas? A nossa hipótese é que esta questão aponta para uma contradição intrínseca entre liberalismo econômico e democracia, entre governamentalização e autogoverno, e esta contradição é responsável, em grande parte, pela crise dos atuais modelos ocidentais de democracia.

O liberalismo econômico é um produto moderno dirigido à gestão governamental da vida. Para entendermos as contradições que se estabelecem entre liberalismo econômico e democracia propomos, num primeiro momento, apresentar alguns elementos da genealogia da governamentalização, segundo as pesquisas de M. Foucault (Barry, Osborne e Rose (orgs.), 1996). Seguindo a tese deste autor, a governamentalidade é uma prática discursiva que, embora não seja exclusiva do poder moderno, constitui sua principal característica (Burchell, Gordon e Miller (orgs.) 1991).

\footnotetext{
Por esta palavra 'governamentalidade', entendo o conjunto de instituições, os procedimentos, análises e reflexões, os cálculos e as táticas que permitem exercer essa forma bem específica, embora muito complexa, de poder que tem por alvo principal a população, por principal forma de saber a economia política e por instrumento técnico essencial os dispositivos de segurança (Foucault, 2008, p. 143).
}

Ainda que durante a Antiguidade e na Idade Média não faltassem tratados de aconselhamento ao príncipe para exercer bem o poder a partir da ótica das boas virtudes do governante, foi durante o século XVI até o século XVIII que vimos florescer uma vasta literatura sobre a problemática do governo cujos tratados não se limitam a dar conselhos ao príncipe, mas se apresentam como artes de governar (Senellart, 1995). Entre os muitos tratados dessa época, talvez 
o mais conhecido seja a obra de Maquiavel, “O príncipe”. Mas essa obra, longe de ser algo excepcional, situa-se dentro de uma corrente discursiva sobre as artes de governar que floresceu de forma muito profícua nessa época.

Foucault, por sua vez, chama a atenção sobre o tratado de Guillaume de La Perrière, 1555, "O espelho político", contendo diversas maneiras de governar (La Perrière, 1567). Neste texto, o autor expõe os significados que os termos governo e governar têm no século XVI: "governar uma casa, governar almas, governar crianças, governar uma província, governar um convento, um ordem religiosa, governar uma família" (Foucault, 2008, p. 124). Para La Perrière a problemática do governo envolve três aspectos: o governador, as pessoas governadas e as artes de governar. O governo do Estado por um príncipe nada mais é que uma das modalidades das artes de governar. Percebe-se nesta visão que há uma imanência das práticas de governo em relação ao Estado. Esta característica do governo, segundo La Perrière, distancia-se do modo como a soberania política absoluta exercia o poder ainda naquele momento. As artes de governo dos séculos XVI ao XVIII indicam que há uma dinâmica imanente ao bom governo que depende da natureza das coisas e que não pode ser ignorada pelo poder soberano. Neste ponto, o tratado de La Perrière diferencia-se, também, das teses de Maquiavel.

Foucault analisa um outro tratado paradigmático, o de François La Mothe Le Vayer, de 1651, “A geografia e a moral do príncipe”, uma série de textos pedagógicos para o Delfim da França (La Mothe le Vayer, 1756). Nesta obra, o autor apresenta três tipos de governo que pertencem cada um a uma ciência particular e uma reflexão específica: governo de si mesmo, que pertence à moral; a arte de governar uma família, que corresponde à economia; e a arte de governar bem o Estado, que corresponde à política. $\mathrm{O}$ autor estabelece uma espécie de continuidade ascendente e descendente entre as diversas artes de governo. $\mathrm{Na}$ linha ascendente, defende que quem quiser governar bem um Estado terá que aprender, primeiramente, a governar bem a si mesmo e a sua família. Na linha descendente, quem adquiriu a arte de governar o Estado, conseguirá governar a sua família e a si mesmo.

As novas artes de governar delinearam uma mudança qualitativa no exercício do poder moderno. No tratado de La Perrière, o autor define: "Governo correto é a correta disposição das coisas, das quais alguém se encarrega para conduzi-las a um fim adequado" (Foucault, 2008, p. 126). Nestas obras, o conceito de governo destaca-se como governo das coisas. Por muito elementar que hoje possa nos parecer, considerar o governo como governo das coisas traz consigo um deslocamento significativo do exercício do poder em relação a como era entendido pelo poder soberano. O poder soberano, na teoria clássica, 
estava demarcado pela noção do bem comum, o soberano deveria governar para o bem dos súditos. Contudo, o conceito de bem comum era concebido como uma obediência às leis. Ora, as leis eram determinadas pela vontade do soberano, logo o poder soberano agia numa espécie de circularidade a partir de si mesmo que definia por lei o que era bem comum. No poder soberano prevalece a lógica da vontade do soberano como reitora do exercício do poder e do governo.

As artes do governo introduzem uma outra perspectiva ao enunciar que o bom governo é aquele que "governa a correta disposição das coisas a um fim adequado". Ou seja, o bom governo está além da mera vontade soberana e deve levar em conta a natureza das coisas. O bom governo moderno está na finalidade das coisas que ele dirige e não na mera vontade soberana do sujeito que governa. Para efetuar um bom governo há de se levar em conta a natureza das coisas, para tanto há de se encontrar técnicas adequadas à natureza e finalidade das coisas que se governa. Esta perspectiva do governo distancia-se da soberania que entende o exercício de seu poder como uma decisão arbitrária, no melhor dos casos sábia, do soberano. Por isso, enquanto o poder soberano encontra na lei seu instrumento maior, as artes de governo perceberam a natureza das coisas como referente e critério racional das suas técnicas de gestão.

As artes de governo dos séculos XVI e XVII operavam com o paradigma da oikos grega e não da polis (Lascoumes, 2004). Ou seja, o modelo de governo remetia aos padrões do pater familias que governava com inteligência e sabedoria as necessidades de todos os seus subordinados. Contudo, as artes de governo modernas entraram em crise ao constatar a insuficiência do paradigma da família para governar a complexidade do Estado moderno. O desenvolvimento do aparelho administrativo das monarquias durante os séculos XVI e XVII evidenciou a insuficiência do modelo do governo familiar para administrar a complexidade das novas burocracias emergentes. Um conjunto de novos saberes indicava, nessa época, que governar era muito mais complexo que ser meramente virtuoso. Entre esses novos saberes há que se destacar a "estatística", ou seja, a ciência do Estado:

Etimologicamente, a estatística, é o conhecimento do Estado, o conhecimento das forças e dos recursos que caracterizam um Estado num momento dado. Por exemplo: conhecimento da população, medida de sua quantidade, medida de sua mortalidade, de sua natalidade, estimativa das diferentes categorias de indivíduos num Estado e de sua riqueza... (Foucault, 2008, p. 365).

A estatística trouxe para dentro das artes do governo a complexidade dos números em relação aos fenômenos sociais. É nesta intersecção das artes de 
governo clássicas e dos novos saberes estatísticos que veremos surgir uma nova ciência denominada de "economia política". Os primeiros economistas denominados de mercantilistas, posteriormente cameralistas, fisiocratas e por fim os liberais aprimoraram o esforço de conectar os novos saberes estatísticos com as artes de governo clássicas. Nesse entrecruzamento surgirá a economia política como uma nova ciência do governo dos comportamentos humanos ou governamentalização da vida humana, cujo objetivo era saber governar as condutas ou comportamentos da população. ${ }^{1}$

Por mais que a denominação "economia política" nos resulte familiar, não deixa de ser um oximoro conceitual que criaria perplexidade a qualquer pensador grego. Para os gregos, as formas do poder da polis são opostas, quase que em essência, aos modos como se governa a oikos. A política é o poder exercido entre iguais, nele ninguém é governado por ninguém, todos deliberam com autonomia e autogestão os destinos coletivos. No máximo, na polis se atribuem responsabilidades para serem exercidas em nome do poder coletivo. O governo da oikos é um comando hierárquico em que o despotes ou dominus conduz de forma soberana as vidas daqueles que lhe estão submetidos. Eis por que uma oikonomia nunca poderia ser política, para os gregos. A oikonomia grega era um poder vinculado diretamente ao governo da oikos, com ênfase na gestão da vida das pessoas que habitavam a oikos. A oikonomia associavase diretamente ao governo da vida humana e de suas necessidades básicas. Enquanto a política grega era o poder da autogestão dos sujeitos, a oikonomia era o poder que gerenciava o comportamento e as necessidades dos outros. O oximoro da economia política, criado pelo poder moderno, não é acidental ou meramente retórico, ele reflete a essência do novo poder que emerge no deslocamento das artes de governo para a gestão econômica da vida na forma de uma nova política sobre a vida.

As artes de governo clássicas ficaram bloqueadas nos modelos tradicionais, que compreendiam que o bom governo dependia quase que exclusivamente das virtudes do governante. Desde o século XVII, novos saberes iam desvelando a complexidade de fenômenos sociais antes percebidos de forma abstrata. A estatística destravou o nó conceitual que vincula a vida humana à criação de riqueza mostrando de forma detalhada que as riquezas de um território são correlativas às vidas das pessoas que nele habitam. A estatística também originou um outro novo saber: a demografia. Por meio da demografia se compreendia,

1 “A expressão de Foucault 'condução das condutas' é talvez a mais próxima do que Max Weber chamou, na Ética protestante e o espírito do capitalismo, de Lebensführung (condução da vida)" (Lemm e Vatter, 2014, p. 4). 
de um lado, de modo mais capilar, a quantificação numérica dos indivíduos num território, mas, de outro, a estatística foi mostrando a estreita correlação que existe entre as vidas humanas e a produção de riquezas. Os novos saberes evidenciavam que os nexos entre a vida e a riqueza requeriam uma nova ciência do governo da vida para melhorar o rendimento da riqueza, essa nova ciência seria a economia política cujo expoente último será o liberalismo econômico. Por tudo isso, o nexo a ser governado pelo liberalismo é a vida humana enquanto vida biológica dos indivíduos de uma espécie (Bonnafous-Boucher, 2001).

Curiosamente este novo objeto a ser governado, a coletividade biológica da vida humana, carecia de um conceito específico. Como denominar esta vida biológica humana a ser governada? Não poderia ser com o conceito de povo, já que este era utilizado pelos pensadores da soberania como um conceito que denotava o sujeito de direitos e sujeito da soberania contratualista. Foi neste ponto que os economistas modernos criaram o conceito de "população".

Não é portanto uma coleção de sujeitos jurídicos, em relação individual ou coletiva, com a vontade soberana. A população é um conjunto de elementos, no interior do qual podem-se notar constantes e regularidades até nos acidentes, no interior do qual podese identificar o universo do desejo produzindo regularmente o benefício de todos e a propósito do qual pode se identificar certo número de variáveis de que ele depende e que são capazes de modificá-lo (Foucault, 2008, p. 98).

Numa espécie de quiasmo conceitual os conceitos de povo e população foram explorados na forma de paralelismo discursivo em que o povo denota o sujeito dos direitos e a população o objeto do governo; o povo representa o novo poder soberano e a população o elemento da governamentalização; o povo desdobra-se em cidadão de direitos e a população refere-se às necessidades biológicas da espécie. Vemos emergir nesta dualidade categorial a bipolaridade da máquina do poder moderno ${ }^{2}$ que compreende os seres humanos, concomitantemente, como povo e população, como cidadãos sujeitos de direitos e população objeto de governo.

Os economistas modernos inventaram a população como uma nova categoria do governo, ou melhor, a ser governada. Ao inserir a população como referência para a nova ciência do governo, os economistas operaram alguns deslocamentos conceituais importantes, em relação às artes de governo clássicas. A nova forma de governar deveria levar em conta a natureza dos fenômenos, neste caso, a realidade da vida humana em sua condição biológica e natural. A estatística 
mostrou para os economistas que há uma estreita relação entre, por exemplo, nascimentos, mortes, doenças e produtividade ou riqueza de um território. A mesma estatística evidenciou, por exemplo, que há um nexo profundo entre as necessidades da população e o modo como esta atua para satisfazer essas necessidades. Mas também os novos saberes estatísticos sinalizaram que havia uma relação próxima entre os comportamentos da população e os movimentos de preços, de compra e venda de mercadorias, de escassez ou excedente de alimentos etc. O modo de vida da população interferia, por exemplo, na forma de organização das cidades. Em todos os casos, a população aparecia, para a nova ciência do governo, como o objeto principal a ser governado. Percebe-se a configuração do que vai ser o: "Nascimento de uma arte ou, em todo caso, de táticas e técnicas absolutamente novas" (Foucault, 2008, p. 140) para o governo das populações.

Mas o que deve ser governado da população? Esta é a nova pergunta que a economia política fez para iniciar os processos de gestão de pessoas. Neste ponto reencontramos nas técnicas dos economistas modernos as duas principais características do poder pastoral, que nunca foram apreciadas pelo poder soberano, a saber: o conhecimento detalhado de cada indivíduo e, concomitantemente, o conhecimento geral das necessidades da população, Omnes et singulatim. O conhecimento do todo e de cada indivíduo delimita a nova arte de governar (Foucault, 1994).

As novas técnicas de gestão de pessoas fizeram surgir um novo marco conceitual e discursivo por meio do qual articularam as tecnologias de governo, esse novo discurso é o da "razão de Estado" (Senellart, 2019). Na razão de Estado persistem elementos do poder pastoral, agora aplicados ao governo da população, já que se reconhece como "uma arte de governar os homens". Porém, a razão de Estado também se diferencia do poder pastoral. Essa arte de governar opera com uma produção de verdades diferentes. A razão de Estado coloca-se a questão: o que é necessário para governar? ${ }^{3} \mathrm{O}$ poder pastoral apelava para a sabedoria, a bondade, justiça, assim como o conjunto de virtudes do pastor a modo de condição necessária para a boa condução do rebanho. Por sua vez, a razão de Estado considera insuficiente esse tipo de verdade para um bom governo. As virtudes de governo do poder pastoral realizavam-se mediante leis justas. A razão de Estado considera que a lei é importante, porém insuficiente para a realização de um bom governo (Foucault, 1980, pp. 37-41). Um bom governo exige o conhecimento da realidade dos governados, até no 
mínimo detalhe. O governo da razão de Estado é compreendido como uma nova ciência, a estatística, em que se governa a partir da natureza das coisas governadas. "Não mais, portanto, corpus de leis ou habilidade em aplicá-las quando necessário, mas conjunto de conhecimentos técnicos que caracterizam a realidade do próprio Estado" (Foucault, 2008, p. 365). Giovani Botero, na sua obra Della Ragioni di Estato, 1589, destaca nos livros VII e VIII da obra a importância, ainda embrionária, da economia, a estatística e a demografia para consolidar a força do Estado (Botero, 1589, pp. 177-224).

A razão de Estado entende que governar significa, principalmente, conduzir a vida dos governados para o fortalecimento do próprio Estado. A razão de Estado produz um deslocamento de finalidade do governo em relação ao poder pastoral. O poder pastoral visa ao bem do rebanho, enquanto a razão de Estado tem como finalidade do governo o próprio Estado. A população, que seria o novo rebanho, é um meio utilizado pela razão de Estado para essa finalidade. A população, para a razão de Estado, torna-se um mero meio para a consecução de um fim, que é preservar e ampliar o poder do Estado. Por isso, para a razão de Estado o governo identifica-se com governo dos outros que, cada vez mais, deriva num governo da conduta dos outros com a de incrementar o poder do Estado. Esse governo das condutas próprio da razão de Estado vai se ocupar de intervir na consciência das pessoas, não para impor de forma amedrontadora ordens, como fazia o poder soberano, mas principalmente para criar uma opinião acorde com os interesses e objetivos de quem governa. Impelido pela nova tendência do governo das condutas, vemos aparecer na razão de Estado, por primeira vez, a categoria de "opinião pública".

Bacon, no ensaio "On Seditions and Troubles" (1625), desenvolve a importância do cálculo utilitário como critério de governo (Bacon, 1884, pp. 113-123). Segundo Bacon, esse cálculo deve levar em conta as riquezas produzidas, os impostos, as taxas etc., mas também é um cálculo que tem por objeto a opinião dos governados em relação ao príncipe. Em Bacon aparece de forma embrionária a importância política da opinião dos governados como um elemento do poder que deve ser governado pelo cálculo. Nas subsequentes décadas, esta temática irá ganhando proporções semelhantes à importância da razão de Estado para a gestão da população. Neste contex to há que se entender a real dimensão das teses de Hobbes a respeito quando na sua obra Behemoth afirma que a força dos poderosos não tem outro suporte senão a opinião e a crença do povo e que o Estado deve se preocupar com a promoção da opinião, pois: "As ações dos homens procedem de suas Opiniões; e no bom governo das Opiniões consiste o bom governo das Ações dos homens, para a sua paz e concórdia" (Hobbes, 1990, p. 115). Encontramos na França do século XVII de 
Richelieu as primeiras campanhas políticas publicitárias, nelas se utilizaram os primeiros panfletos que visavam construir uma opinião pública favorável ao governo. A rigor, Richelieu teria inventado este tipo de técnica publicitária dos panfletos, com objeto de construir um tipo de opinião pública acorde com seus objetivos de governo. "Nascimento dos 'economistas', nascimento dos 'publicistas'. São os dois grandes aspectos do campo de realidade, os dois aspectos correlativos do campo de realidade que aparece como correlativo do governo: a economia e a opinião" (Foucault, 2008, p. 363).

A opinião pública aparece como nova categoria inserida na tendência da governamentalização das condutas que a razão de Estado tinha desenhado desde o século XVII. Uma das estratégias modernas de governo será intervir sobre a opinião pública para, por meio de seu alinhamento, conduzir o comportamento da população para agir como "sujeitos econômicos" e "sujeitos políticos". Esta perspectiva mostra que a razão de Estado há de interferir na opinião pública para conduzir os comportamentos da população segundo as metas ou objetivos propostos pelo governo. Sendo assim, a razão de Estado opera com o princípio da governamentalização das condutas. A moderna eficiência do governo não advém da imposição autoritária do poder, como preconizava o poder soberano, mas da possibilidade de conduzir habilidosamente e com o mínimo de resistência a conduta da população. A razão de Estado encontrará na produção e condução da opinião pública um novo espaço de poder, identificado como nova forma de governo.

Por fim, em terceiro lugar, ainda nessa ordem da prática da verdade, o problema do público, quer dizer, que a razão de Estado deve intervir sobre a consciência das pessoas, não simplesmente para lhes impor um certo número de crenças verdadeiras ou falsas, como quando os soberanos queriam fazer crer em sua legitimidade ou na ilegitimidade do seu rival, mas de maneira que a opinião delas seja modificada e, com a opinião delas, a maneira delas agirem, seu comportamento como sujeitos econômicos, seu comportamento como sujeitos políticos. É todo esse trabalho com a opinião do público que vai ser um dos aspectos da política da verdade da razão de Estado (Foucault, 2008, p. 367).

A caracterização da opinião pública como novo espaço de poder na razão de Estado tem um viés meramente passivo. Ou seja, a opinião pública é uma representação que os indivíduos têm do governo e dos governantes. Para os teóricos da razão de Estado do século XVII, a opinião pública é algo que deve ser produzido pela própria razão governamental do Estado com objetivo de incutir na mente dos indivíduos, os governados, uma determinada opinião, uma visão da realidade (Foucault, 2008, p. 370).

Foucault ampliou suas pesquisas sobre o neoliberalismo do século XX indicando que nele se produziu um deslocamento significativo dos modelos 
governamentais do liberalismo clássico, sendo o homo oeconomicus o novo modelo de subjetivação neoliberal. A característica principal do homo oeconomicus seria sua potencial mercantilização de todas as capacidades vitais e até biológicas. O homo oeconomicus deve aprender a se converter num empresário de si. O princípio orientador do homo oeconomicus é que a reprodução da vida pode ser reconvertida numa empresa (Foucault, 2004, p. 232). Tudo que ele é como indivíduo biológico pode tornar-se objeto de empreendimento econômico. O mercado não seria um mero espaço de trocas, como o concebia o liberalismo clássico, mas uma relação entre empresas humanas constituídas pelos indivíduos agora estabelecidos como empresários de si mesmos. Nesta nova visão do mercado, o indivíduo tem em si mesmo o capital, ele se torna produtor e, no lugar do salário proveniente do aluguel da força de trabalho, pode obter renda pela exploração comercial de suas potencialidades. Ele se torna um empreendedor e constitui-se, antes de mais nada, num sujeito econômico (Foucault, 2004, p. 233).

O paradoxo do neoliberalismo é que ele exige a liberdade como condição necessária do homo oeconomicus, inclusive produz a liberdade como exigência dos indivíduos econômicos. Diferentemente da noção de liberdade natural própria do liberalismo clássico, o neoliberalismo irá desenvolver um conceito de liberdade arranjada, da qual surge a conduta empresarial dos indivíduos (Lemke, 2017, pp. 19-20). Mesmo com a defesa e produção da liberdade do homo oeconomicus, o neoliberalismo não renuncia à governamentalização dos indivíduos. O desafio da nova governamentalidade neoliberal consistirá em governar a liberdade incentivando-a e sem constrangê-la a ponto de negá-la. Ou seja, como respeitar e exigir a liberdade como natureza essencial do homo oeconomicus e concomitantemente conseguir geri-la. A razão governamental neoliberal deve produzir a liberdade para consumi-la, para tanto formula o princípio da liberdade dos indivíduos como condição necessária de sua natureza econômica, não obstante deve estabelecer os limites dentro dos quais haverão de exercê-la (Foucault, 2004, p. 65).

Entre outros, Foucault analisa o pensamento neoliberal de Gary Becker, que pensa que as condutas humanas sendo livres não são totalmente aleatórias (Foucault, 2004, p. 272). Becker entende que toda liberdade age a partir dos condicionamentos do meio. Ou seja, o indivíduo atua livremente, porém sempre reagindo às interferências ou condicionamentos do meio em que atua (Becker, 1962, pp. 9-49). O homo oeconomicus sempre atua com uma mentalidade utilitarista. Para Becker, a junção desses dois princípios - a mentalidade utilitarista e sua reação aos condicionantes do meio - pode oferecer uma alternativa para a governamentalização da liberdade. Pois, ao interferir sobre 
o meio, provocar-se-á uma reação nos indivíduos que tenderão a adaptar seus interesses aos novos condicionamentos. Nesse caso, intervindo sobre o meio se consegue a mudança das condutas dos indivíduos numa direção previsível pela procura de maior utilidade e vantagem pessoal. Isso pode ser feito respeitando a liberdade individual. Foucault analisa como a governamentalidade econômica neoliberal encontrou nas teses de Becker uma espécie de tecnologia de governo mediante e qual se respeita a livre decisão dos indivíduos, porém se consegue interferir sobre suas condutas com alto índice de previsibilidade.

O homo oeconomicus é aquele que é eminentemente governável. De parceiro intangível do laissez-faire, o homo oeconomicus aparece agora como correlativo a uma governamentalidade que vai agir sobre o meio e vai modificar sistematicamente as variáveis do meio (Foucault, 2004, p. 274).

A tecnologia governamental do neoliberalismo que reduz a ação humana aos princípios do homo oeconomicus conduz ao que Mises denominou de democracias de consumidores (Mises, 1998, p. 270), nas quais vigora o princípio do interesse próprio livremente exercido. A governamentalização dos interesses individuais por meio da interferência nas variáveis do meio conduzirá, inexoravelmente, a uma governamentalização das democracias. Foucault não ampliou as pesquisas sobre a importância da opinião pública como tecnologia governamental e sua relação com as democracias contemporâneas. Algo que, como veremos a seguir, Agamben se propôs a dar sequência.

\section{A governamentalização da democracia: a hierarquia burocrática}

As pesquisas de Foucault a respeito da governamentalidade liberal apontaram para dois aspectos que consideramos cruciais em relação às democracias modernas, a saber, a substituição do povo pela população e o desenvolvimento da opinião pública como tecnologia para gerenciar a conduta da população. A seguir, analisaremos como as atuais democracias transformaram-se no oximoro representado nas democracias de massas e posteriormente nas democracias espetaculares, como consequência direta e imediata dos dispositivos de governamentalização amplamente disseminados pelo conjunto do tecido social.

Agamben identifica nas democracias modernas um duplo sentido, que nem sempre é percebido pelo senso comum. Quando falamos de democracia: "pode significar uma de duas coisas diferentes: um modo de constituir o corpo político (em este caso estamos falando de direito público) ou uma técnica de governo (caso em que o nosso horizonte é o da administração prática)" (Agamben, 2011b, p. 1). Nessa dupla acepção da democracia, encontram-se implícitas 
as duas dimensões do poder moderno, a saber, o poder soberano e a técnica de governar. A rigor, a bipolaridade soberania e governo está implícita no modo como designamos à democracia atual. Esse duplo sentido da democracia, segundo o autor, já está presente na Grécia antiga em que o uso do termo politeia significava tanto a constituição (poder soberano) como o governo. Essa bipolaridade do sentido da democracia ressurge nos primeiros teóricos da modernidade (Agamben, 2011b, p. 3).

Agamben, dando sequência às pesquisas de Foucault, apresentou novas teses que, não invalidando as de Foucault, mostram perspectivas inovadoras na correlação existente entre a oikonomia política e as democracias modernas. Agamben parte da tese de que o poder moderno se constitui a modo de uma máquina bipolar que articula a soberania e o governo. Os dois eixos da máquina bipolar têm em comum a captura e o governo da vida humana. A soberania captura a vida humana sob a forma de exceção, enquanto o governo a gerencia como um insumo biológico. A vida humana é, para a máquina bipolar, o referente a ser capturado e governado; por isso o poder moderno é intrinsecamente biopolítico (Mcgovern, 2011, pp. 213-223; Primera, 2015). Agamben detecta importantes aspectos da oikonomia que penetraram nas democracias modernas tornando-as "democracias espetaculares" esvaziando as democracias do princípio originário do cratos em relação ao demos (Ross, 2006, pp. 74-85). Como consequência, as democracias são transformadas num espetáculo em que o povo se tornou um espectador que participa no ato de opinar. "O 'devir da imagem do capital' não é senão a última metamorfose da mercadoria, na qual o valor de troca, desde então, eclipsou totalmente o valor de uso e, depois de ter falsificado toda produção social, pode agora aceder a um estatuto de soberania absoluta e irresponsável sobre toda a vida" (Agamben, 2015, p. 74). Entre outros aspectos assinalados por Agamben como elementos que descaracterizam o sentido democrático das atuais democracias, destacamos neste estudo dois: a hierarquia burocrática e os dispositivos de glorificação.

Agamben, à diferença de Foucault, entende que a genealogia da economia política moderna deve retroagir até os debates teológicos cristãos dos séculos III e IV d.C. em relação ao problema da criação livre do mundo por Deus e a liberdade humana, assim como o governo livre do mundo e dos homens por Deus (Kotsko, 2014, pp. 107-114). Nesta dupla dimensão divina, a teologia cristã cristalizou, de um lado, o sentido da soberania divina que transcende o mundo, de outro, a imanência de Deus no mundo por meio do seu governo. "Do primeiro paradigma derivam a filosofia política e a teoria moderna da soberania; do segundo, a biopolítica moderna até o atual triunfo da economia e do governo de qualquer outro aspecto social" (Agamben, 2011a, p. 13). 
Dos vários elementos condizentes com a governamentalidade moderna, Agamben prestou especial atenção à burocracia, algo que as pesquisas de Foucault já tinham localizado como relevante, porém sem um desenvolvimento explícito mais amplo (Foucault, 2008, pp. 383-417). Agamben, coerente com a tese de que a política moderna é em muitos aspectos uma secularização de teologia cristã, mostra que para compreendermos muitos dos processos modernos de burocratização da gestão temos que nos remeter aos tratados teológicos cristãos, que se preocuparam em analisar como Deus pode governar o mundo por meio de intermediários.

Ao longo do pensamento filosófico encontramos ampla produção discursiva a respeito da temática da soberania, porém há pouca reflexão filosófica sobre o governo. Diferentemente da filosofia, durante séculos não cessaram de se escrever tratados de teologia em torno da temática do governo e suas diversas questões. Agamben chama a atenção que a problemática teológica do governo abrange tanto as questões filosóficas a respeito da liberdade quanto as questões práticas em torno da burocracia (Toscano, 2011, pp. 125-136). Para Agamben, a genealogia do poder moderno oculta as assinaturas teológicas secularizadas (Agamben, 2009), porém a suposta secularização não desativou a vigência dessas assinaturas que continuam ativas dentro dos dispositivos de poder modernos (Ludueña Romandini, 2011, pp. 99-113). Primeiramente, há que se desvendar essas assinaturas teológicas para entendermos como operam as novas formas de dominação social.

No caso da burocracia, segundo Agamben, também encontramos na teologia a matriz genealógica desta importante questão para a governamentalidade (Gignac, 2019). Um primeiro aspecto a ser destacado da genealogia da burocracia é o conceito de hierarquia. Toda burocracia, diferentemente da democracia, opera por hierarquias. Foi Dionísio Areopagita quem dedicou um tratado completo ao tema da hierarquia com o título $A$ hierarquia celeste (Dionísio Areopagita, 2015). "A invenção do termo hierarchia é a contribuição específica do autor, cujo vocabulário é, de resto, fortemente dependente de Proclo. Como Tomás observa oportunamente, o termo não significa 'ordem sagrada', mas 'poder sagrado"' (Agamben, 2011a, p. 170). Este tratado, mesmo sendo apócrifo, serviu de modelo para consolidar a hierarquia eclesiástica como imitação da hierarquia celeste. A rigor, o tratado oferece o modelo para todas as hierarquias, uma vez que as instituições não eclesiais imitarão o modelo burocrático da gestão hierárquica proposto pelo tratado, implementado com bom sucesso pela Igreja. O governo hierárquico de Deus se faz por meio dos anjos. Eis por que a doutrina sobre os anjos, hoje tão desprezada, teve uma grande importância durante séculos, pois dela dependia a compreensão correta 
do bom governo divino do mundo e das pessoas. Os anjos são os funcionários de Deus.

A introdução de um tema hierárquico na angelologia - ou antes a invenção do próprio termo "hierarquia" - é obra de um apócrifo, cujo gesto é uma das mistificações mais tenazes da história da literatura cristã e ainda espera para ser desvelado.

$[\ldots]$

De qualquer maneira, uma leitura que tenha se libertado do anteparo da interpretação translatícia não deixa dúvidas quanto à estratégia do apócrifo, que apresenta logo depois de sua Hierarquia celeste uma Hierarquia eclesiástica: trata-se, de um lado, de hierarquizar os anjos, dispondo as fileiras segundo uma ordem rigidamente burocrática e, de outro, de angelizar as hierarquias eclesiásticas, distribuindo-as segundo uma gradação essencialmente sacral (Agamben, 2011a, pp. 169-170).

O tratado teve uma grande influência na organização da estrutura social durante toda a Idade Média e, posteriormente, a noção de hierarquia será incorporada ao governo moderno como elemento constitutivo da diferenciação funcional tanto no Estado quanto na gestão corporativa. Cada gestor está submetido a um superior imediato, ao qual deve obedecer e dar resposta de todas suas ações corporativas.

Para a filosofia jurídica, a problemática do governo e sua estrutura burocrática estava ausente do seu horizonte reflexivo por ser considerada uma questão prática menor. Foi a teologia a área do saber que lhe dedicou uma maior atenção e desenvolveu uma longa e larga reflexão sobre o sentido político da burocracia. Agamben propõe, como exemplo, a importância que Tomás de Aquino deu ao problema da burocracia e da hierarquia no opúsculo de De gubernatione mundi, em sua magna obra Summa Teologica (Agamben, 2011a, p. 147). Neste capítulo, Tomás de Aquino pensa como será a organização do governo do mundo por Deus a partir de uma sofisticada organização de intermediários. Deus teria seus ministros para governar, que seriam os anjos. Os termos ministros e ministérios são oriundos da teologia cristã, eles são aplicados àqueles que exercem a função (funcionários) em nome de outro. Para Tomás, a utilização de ministros não diminui a potência do governo, senão que aperfeiçoa o modo de fazê-lo:

Isso é precisamente o que constitui a razão do seu ministério, porque o ministro é como um instrumento de caráter racional e o instrumento é sempre movido por outro e a outro também se ordena a sua ação. Por isso, as ações dos anjos são chamadas de ministérios; e por isso se diz que os anjos são enviados em ministério (Tomás de Aquino, 2001, C.112.a2).

Tomás de Aquino chega, inclusive, a conceber a distinção entre ministros assessores e ministros executores, que ele denomina como anjos assistentes e 
anjos administradores. Os primeiros estão diretamente na presença de Deus, na contemplação, e recebem as ordens diretamente de Deus. Os segundos estão numa escala hierárquica inferior e recebem as ordens dos primeiros. "Se os anjos superiores não são enviados em ministério exterior, será porque estes executam os ofícios divinos por meio dos inferiores. Mas, ao serem todos os anjos desiguais, como dissemos, para cada anjo há outro inferior, exceto para o último" (Tomás de Aquino, 2001, C.112.a2). Como mostra Agamben, nos tratados teológicos encontramos muitas categorias conceituais do governo utilizadas em nossos dias, assim como aprecia-se uma influência destes tratados no que será a burocracia moderna (Agamben, 2011a, p. 175).

$\mathrm{Na}$ medida em que a política moderna é capturada pela oikonomia, a democracia também é contaminada pelo princípio oikonomico da gestão burocrática das deliberações. Desse modo, a hierarquia penetra nas democracias contemporâneas por meio do caráter governamentalizador que as vai contaminando. Nesse caso, e mais uma vez, confrontamo-nos com um oximoro de nossas democracias: a gestão burocrática das deliberações livres dos cidadãos. À medida que as democracias vão transferindo, cada vez mais, o dispositivo (democrático) da deliberação para o dispositivo (econômico) da burocracia, a democracia torna-se mais uma governamentalização oikonomica das condutas dos cidadãos realizada mediante a gestão hierárquica das decisões na forma da delegação de um poder vicário.

A dúplice (ou tríplice) estrutura da máquina governamental (Reino e Governo, auctoritas e potestas, ordinatio e executio, mas também a distinção dos poderes nas democracias modernas) adquire nessa perspectiva seu sentido próprio. $\mathrm{O}$ governo age vicariamente com respeito ao Reino; mas isso tem sentido só no interior de uma economia de funções, em que nenhum poder pode prescindir do outro (Agamben, 2011a, p. 156).

Temos aqui desenhado um ponto crítico de tensão entre a oikonomia e as democracias contemporâneas. Essa tensão ocorre porque as democracias, cada vez mais, são gerenciadas como espaços oikonomicos (Agamben, 2011b, p. 4). Nas atuais democracias, o princípio da isonomia torna-se mais formal que real, prevalecendo sobre a isonomia da cidadania as hierarquias funcionais do aparato burocrático. Concomitantemente, e à medida que a economia vai-se sobrepondo sobre a própria democracia, os modelos corporativos de gestão vão substituindo os princípios democráticos de deliberação. Talvez possamos encontrar neste paradoxo da governamentalidade um dos aspectos pelos quais as democracias contemporâneas vão perdendo seu caráter de deliberação pública e se tornando, cada vez mais, um espaço de mera gestão de necessidades. 


\section{Democracia de massas \& democracias espetaculares}

As pesquisas de Foucault já tinham mostrado como a governamentalização da população propiciou o surgimento do conceito de "opinião pública". Esta formava parte da razão de Estado para conseguir dirigir os comportamentos da população. Agamben deu prosseguimento a esta tese de Foucault ampliando a pesquisa a respeito dos nexos que existem entre a opinião pública e os dispositivos de glorificação em relação aos modelos atuais de democracia que Agamben denominou de democracia espetacular. Para Agamben, uma questãochave desta pesquisa, já apresentada pelo autor no início da sua obra $O$ reino e a glória, é saber: por que o poder necessita de glória? (Agamben, 2011a, p. 10). Esta questão pode se desdobrar, interrogando: como é que as democracias modernas necessitam apelar permanentemente para dispositivos de glorificação do poder a fim de manter a sua legitimidade? Por que a estabilidade de um poder democrático depende tanto de cerimônias, protocolos e liturgias, sem as quais sua legitimidade jurídica é insuficiente e pode balançar e até sucumbir? Agamben percebe que nestas questões há um nexo, muitas vezes oculto, entre a soberania e o governo, e se faz necessário desvendar esse elo oculto para termos uma leitura crítica da máquina bipolar do poder moderno.

Um dos nexos ocultos do poder moderno seria sua relação com os dispositivos de glorificação. A glória é um atributo divino e uma categoria teológica (Dickinson, 2017). Contudo, ela já era amplamente utilizada nas formas clássicas de soberania absoluta. O soberano, para legitimar sua soberania perante os súditos, necessitava maquiar o poder com a fastuosidade das cerimônias. Embora as formas de glorificação da soberania pareçam ser algo superado pelo forte matiz religioso e sagrado que carregam consigo, o poder moderno atualizou as formas de glorificação do poder, mas nunca renunciou a elas. Isso é mais um indício de que a pretensa secularização moderna não aboliu as assinaturas do sagrado das instituições ou práticas políticas modernas (Catroga, 2006). ${ }^{4}$ As formas de glorificação utilizam-se dos ritos como significantes do poder. O rito é sempre uma expressão das formas de glorificação (Kantorowitz, 1998). O rito em muitos casos enaltece o poder, em outros, inclusive, o poder depende do rito. O poder moderno, que nunca se desprendeu das liturgias e seu caráter performativo, produziu uma infindável sequência de ritos mediante os quais se consolida e até se legitima como poder.

4 Em vários aspectos, a obra de Catroga referenda a tese de Agamben, como quando afirma: "[...] uma transferência do conteúdo, dos esquemas e dos modelos elaborados no campo religioso, para o campo profano, o que acaba por relativizar a novidade radical dos tempos modernos, assim reduzidos à condição de herdeiros, não obstante todas as suas ilusões de auto-fundação" (2006, p. 17). 
Os atos de investidura do poder talvez sejam um dos maiores exemplos da relação entre significante e significado ritual do poder. Alguém não poderá exercer legitimamente o poder se não tiver passado pelo rito da investidura. Sem a investidura o poder não pode ser exercido e por meio dela o poder é transferido numa espécie de performatividade significativa que se parece muito com o rito da liturgia sacramental. As liturgias são inerentes às formas de legitimação e exercício do poder moderno: "Nas recepções e nas cerimônias solenes, o presidente da república continua seguindo regras protocolares, cuja observância é delegada a funcionários especiais..." (Agamben, 2011a, p. 276).

De todas as formas rituais e litúrgicas do poder moderno, Agamben destaca a importância da opinião pública como dispositivo moderno de glorificação do poder das democracias modernas. A opinião pública não só se tornou uma técnica de governamentalização da população, como analisou Foucault, senão que ela opera como um dispositivo de glorificação essencial para a estabilidade e permanência de qualquer poder moderno, segundo as teses de Agamben. A estabilidade dos governantes das democracias atuais depende da opinião pública, caso esta tenha índices muito baixos de aprovação, um governo coloca em risco sua própria sobrevivência. $\mathrm{O}$ dispositivo da opinião pública desdobrou-se em muitas facetas, por exemplo, as pesquisas de opinião dos eleitores podem decidir efetivamente uma eleição; a opinião de confiança dos consumidores mostra tendências comportamentais etc. O poder depende, cada vez mais, dos dispositivos da opinião pública.

Outrossim, fica cada vez mais evidente que a opinião pública não existe de forma natural ou espontânea. Se desde o século XVIII já percebemos que a opinião pública emergiu na teoria da razão de Estado como um espaço de intervenção do poder do Estado para seu próprio benefício, no atual estágio, a opinião pública sofre amplas interferências de múltiplos dispositivos de poder que se utilizam das mais sofisticadas tecnologias para influenciar as diversas opiniões das pessoas sobre qualquer aspecto relevante para a vida social. A opinião pública é fabricada, em grande parte, por dispositivos de comunicação. Quanto maior for o poder de penetração de um dispositivo de comunicação, mais influência terá na criação da opinião pública. Logo, as democracias modernas estão reféns destes mecanismos de legitimação midiática. Esta dependência tão estreita levou Agamben a denominar as democracias atuais de democracias espetaculares, como veremos a seguir.

Agamben analisa a importância política do ritual da aclamação, inerente à glorificação. Neste ponto retoma, de forma crítica, o estudo de Carl Schmitt sobre o valor político da aclamação (Schmitt, 2001). Em 1928, Carl Schmitt escreveu o ensaio Referendum e proposta de lei de iniciativa popular. Neste ensaio 
Schmitt analisa o valor jurídico das aclamações no direito público. Schmitt parte do princípio de que o povo só existe na publicidade, ou seja, quando se manifesta publicamente. Inclusive Schmitt associa-se às teses da democracia direta de Rousseau, segundo as quais o povo não pode ser representado. Só o povo reunido de forma pública pode fazer a ação política por excelência, já que só esta expressa a vontade popular que, segundo Schmitt, se realiza na forma de "aclamação". A aclamação representa o ato de soberania popular por excelência. O povo reunido, ao aclamar das diversas formas possíveis, realiza o exercício pleno da soberania. Para Schmitt, a aclamação é a expressão clara do que ele denomina de democracia pura. "De fato, a verdadeira atividade, capacidade e função do povo, o núcleo de toda expressão popular, o fenômeno democrático originário, o que também Rousseau projetou como verdadeira democracia, é a aclamação, o grito de aprovação ou rejeição da massa reunida" (Schmitt, 2001, p. 62). Fica evidente que por trás da democracia pura de Schmitt ecoam as experiências fascistas e nazista, assim como caudilhismos de todos os signos, de aclamação do líder.

De outro lado, o valor jurídico da aclamação no reconhecimento da soberania política remete, para Schmitt, ao sentido da aclamação litúrgica cristã. A liturgia cristã sempre entendeu que a aclamação é um rito por meio do qual se glorifica, de forma plena, a soberania divina. Agamben segue o estudo de Erick Peterson e pergunta: o que é uma aclamação? Esta pode ser definida como uma "exclamação", que por sua vez pode ser de aprovação ou reprovação, de concordância ou discordância, de louvor ou crítica. Em Roma a aclamação vinha acompanhada de vários gestos, como erguer a mão direita, o aplauso, agitar lenços. Agamben também reporta-se aos estudos de Erik Peterson e afirma que: "A fórmula Heis theos é uma aclamação e não uma profissão de fé” (Agamben, 2011a, p. 187). Desse modo, as aclamações da liturgia cristã remetem, de forma obscura, às aclamações dos imperadores romanos e ainda às aclamações com as quais, inclusive, saudavam a epifania de Dionísio nos rituais órficos. Segundo Peterson, a aclamação tem um nexo essencial que une direito e liturgia (Agamben, 2011a, p. 189). Como veremos a seguir, esta tese de Peterson será seguida por Schmitt e estaria vigente nas modernas formas de aclamação midiática.

Num outro argumento, Schmitt reconhece que nas sociedades atuais é impossível realizar as assembleias de todo o povo para aclamar. Por isso, segundo Schmitt, a aclamação sobrevive nas democracias contemporâneas na forma de "opinião pública". "A opinião pública é a forma moderna da aclamação [...] Não há nenhuma democracia e nenhum Estado sem opinião pública, assim como não há Estado sem aclamação" (Schmitt, 1938, p. 320). 
Segundo a tese de Schmitt, a aclamação litúrgica retornou ao espaço público das democracias puras na forma aclamatória da opinião pública. Neste ponto, Agamben conecta de forma crítica as teses de Schmitt com o atual formato das democracias burguesas, já que, de modo muito paradoxal, percebe-se que as democracias atuais aderiram às teses de Schmitt ao considerar, ainda que implicitamente, que a opinião pública é o dispositivo que confere estabilidade e legitimidade ao governo, porque ele expressa a vontade pública desse momento.

Essa descoberta científica da aclamação é o ponto de partida para uma descrição dos procedimentos da democracia direta ou pura. Não se pode menosprezar o fato de que, onde quer que exista uma opinião pública como realidade social e não apenas como pretexto político, em todos os momentos decisivos em que o senso político pode afirmar-se, comparecem em primeiro lugar aclamações de aprovação ou de rejeição, independentes de um procedimento de votação, pois por intermédio de semelhante procedimento elas poderiam vir ameaçadas em sua genuinidade, enquanto a imediatidade do povo reunido que define tais aclamações acaba anulada pelo isolamento de cada votante e pelo segredo eleitoral (Schmitt, 2001, p. 62).

Num outro deslizamento conceitual, Agamben relaciona as teses anteriores de Schmitt com os estudos de Guy Debord sobre $A$ sociedade do espetáculo (Debord, 1992), para melhor compreender o atual alcance da opinião pública como dispositivo legitimador fático das democracias modernas. Debord constata que a economia capitalista transformou a política num imenso espetáculo em escala planetária: "Tanto mais notável é o gesto com o qual Debord funda precisamente nesse traço flagrante sua análise da sociedade do espetáculo, isto é, o capitalismo que chegou a sua figura extrema" (Agamben, 2015, p. 74). A política (e a democracia) teriam se tornado um ingente acúmulo de espetáculos em que tudo se transforma em imagem preelaborada. "Toda vida das sociedades nas quais reinam as condições modernas de produção, se anuncia como uma imensa produção de espetáculos. Tudo que é vivido se esvai na fumaça da representação" (Debord, 1992, p. 10). Agamben conecta a análise sobre o alcance do espetáculo com os estudos sobre a opinião pública, com objetivo de conseguir obter algumas conclusões críticas mais contundentes.

Uma nova e inaudita concentração, multiplicação e disseminação da função da glória como centro do sistema político. O que estava antes confinado às esferas da liturgia e dos cerimoniais concentra-se agora na mídia e, por meio dela, difunde-se e penetra em cada instante e em cada âmbito, tanto público quanto privado da sociedade. A democracia contemporânea é uma democracia inteiramente fundada na glória, ou seja, na eficácia da aclamação, multiplicada e disseminada pela mídia além do que se possa imaginar (Agamben, 2011a, p. 278). 


\section{Algumas conclusões}

As pesquisas de Foucault sobre o papel da opinião pública na razão de Estado possibilitaram a Agamben apontar para novos desdobramentos, mediante o cruzamento da genealogia da opinião pública com a dimensão espetacular das atuais sociedades.

Esse estudo nos permite compreender criticamente o domínio espetacular da mídia sobre qualquer aspecto da vida social que transforma a opinião pública numa opinião midiática, ou melhor dizendo, numa opinião espetacular (López, 2016, p. 799). As possibilidades de ingerência midiática na elaboração da opinião pública tornaram-se do domínio do espetáculo. Tudo que é verdadeiro aparece como espetáculo, ou não mais será aceito como verdade. Este princípio espetacular atinge quase todos os aspectos das atuais democracias. "A sociedade do espetáculo - se denominarmos assim as democracias contemporâneas - é, desse ponto de vista, uma sociedade em que o poder em seu aspecto 'glorioso' se torna indiscernível com relação à oikonomia e ao governo" (Agamben, 2011a, p. 10).

Vejamos exemplos: a votação livre assemelha-se, cada vez mais, à compra de um produto. Os candidatos, cada vez mais, têm que ser bons atores, com maquiagem, linguagem, roupagem e um roteiro pré-escrito do que dizer e como dizer. O candidato com mais chances de ganhar é quem tem mais tempo de publicidade. Vemos consumados atores, jogadores de futebol, radialistas, até humoristas etc., transformarem-se em políticos com altíssimo índice de votação. O programa político é um produto que se vende seguindo as estratégias de marketing de qualquer produto comercial, que estudam previamente o gosto dos consumidores. Ficou demonstrada a influência nos resultados de eleições políticas de vários países de empresas especializadas em produzir robôs para envio de mensagens em grande escala para induzir a opinião das pessoas (Diebel- Fischer, 2018, pp. 8-19). Vemos consolidar-se o modelo de algoritmização da vida como método para induzir de forma altamente subreptícia o comportamento dos indivíduos (Berry, 2017; Sadin, 2015). As redes sociais, que pareciam um terreno de liberdade e espontaneidade perante a mídia convencional, são altamente patrulhadas por empresas e dispositivos de formatação de opinião e conduta (Acioli, 2007, pp. 8-19; Rivoltella, 2008).

A necessidade de sofisticadas tecnologias como ferramentas da burocracia é uma das maneiras de legitimar a prática governamental moderna como poder que se sobrepõe à deliberação política. Neste debate, não se questiona a importância do uso das tecnologias para uma boa gestão, porém problematizase a inversão de sentido político dado às tecnologias, uma vez que o fato de serem imprescindíveis para a gestão das complexas sociedades contemporâneas 
não significa que possam substituir o princípio da deliberação política pelas estratégias de gestão dos comportamentos. Outrossim, sempre é conveniente destacar que, por mais sofisticadas e condicionantes que sejam as estratégias de governamentalização dos sujeitos, nunca conseguem capturar de forma absoluta a potência da deliberação. A potência da ação humana nunca se esgota no agir, contendo a possibilidade da imprevisibilidade na ação. Os dispositivos de controle amplamente desenvolvidos condicionam fortemente os comportamentos das populações, a ponto de conseguirem direcionar com muita previsibilidade suas condutas. Mas nunca existe o controle absoluto da ação humana, esta conserva uma potência inapreensível pelos dispositivos governamentais. Isso torna a potência da imprevisibilidade da ação humana uma linha de fuga aberta. Poderíamos dizer que as estratégias de controle deslocaram para a subjetividade humana um espaço nevrálgico do poder moderno. Nesse espaço há uma tensão sempre aberta entre as possibilidades do gerenciamento dos indivíduos e a imprevisibilidade potencial de sua ação.

Com base nestas realidades, entendemos a pertinência da tese de Agamben quando afirma que as democracias ocidentais tornaram-se, cada vez mais, democracias aclamatórias no sentido que Schmitt preconizava. Embora a crítica que Schmitt fez às democracias liberais perca força ao constarmos que cada vez mais a democracia liberal se assemelha ao modelo de democracia pura proposto pelo próprio Schmitt, já que nos encontramos numa espécie de dinâmica circular que ao converter a democracia liberal numa democracia espetacular se transformou num novo tipo de democracia pura ou aclamatória, propugnado por Schmitt.

Se, partindo do termo grego para "povo", demos, chamamos essa experiência de "ademia", então ademia será, para o poeta e para o filósofo - ou melhor, para o poetafilósofo e para o filósofo-poeta-, o nome do nexo indissolúvel que une a poesia e a filosofia e, a um só tempo, o nome da política em que se vive (a democracia em que hoje vivemos é essencialmente ademia - é, portanto, uma palavra vazia) (Agamben, 2018, p. 95).

Uma outra conclusão relevante é que, para Agamben, a importância adquirida pelos meios de comunicação nas democracias modernas não se deve só ao fato de que permitem o controle e a produção da opinião pública, senão: "também e sobretudo porque administram e dispensam a Glória, aquele aspecto aclamativo e doxológico do poder que na modernidade parecia ter desaparecido" (Agamben, 2011a, p. 10).

O que ficava confinado nas liturgias e cerimônias da soberania glorificando-a como algo absoluto agora se concentra nos meios de comunicação por meio dos quais os novos ritos de aclamação da opinião pública realizam também um novo 
tipo de glorificação. “O caráter fundamentalmente tautológico do espetáculo decorre do simples fato de que seus meios são ao mesmo tempo seu propósito. Ele é o sol que nunca se põe no império da passividade moderna. Abrange toda a superfície do mundo e banha-se indefinidamente em sua própria glória" (Debord, 1992, p. 13). Estas novas formas de glorificação das democracias espetaculares permeiam os âmbitos tanto público quanto privado, que ao disseminar as formas de aclamação e glorificação do poder vigente contribuem para sua legitimação social. O poder espetacular tem por objetivo legitimá-lo socialmente como o melhor poder.

Este estudo nos leva a entender que as democracias modernas deslizaramse, perigosamente, para o espetáculo, tornando-se democracias espetaculares. Elas operam mediante a constante intervenção sobre a opinião pública como principal dispositivo de aclamação das massas. As democracias modernas substituíram o povo pela massa e a deliberação consciente e crítica pela fabricação da opinião pública. Não é, pois, de estranhar que Agamben afirme que as democracias atuais caminham perigosamente para o oximoro de se tornarem, em muitos casos, democracias autoritárias.

\section{Referências}

ACIOLI, S. "Redes Sociais e Teoria Social: revendo os fundamentos do conceito". Informação \& Informação. Universidade Estadual de Londrina, Vol. 12, 2007, pp. 8-19. AGAMBEN, G. "Em nome de quê?". In: . O fogo e o relato. São Paulo: Boitempo, 2018.

. "Introductory note on the concept of democracy". In: A. Allem (org.). Democracy in what state? New York: Columbia University Press, 2011b.

. "Meios sem fim. Notas sobre a política". Rio de Janeiro: Autêntica, 2015.

"O reino e a glória. Uma genealogia da economia e do governo. Homo Sacer II, 2.” São Paulo: Boitempo, 2011a.

. "Signatura rerum. Sobre el método." Buenos Aires: Adriana Hidalgo, 2009. BACON, F. "On Seditions and Troubles". In: . Essays. Boston: Cambridge, 1884. pp. 113-123 [Online]. Disponível em: http://restorationchristianculture.org/wpcontent/uploads/baconsessayswisd00bacoiala.pdf(Acessado em 24 de março de 2019). BALIBAR, E. "The Politics of Debt." [Online]. Disponível em: http://criticaltheory. berkeley.edu/events/event/neoliberalism-and-biopolitics-working-group-politics-ofthe-debt/ (Acessado em 20 de fevereiro de 2019).

BARRY, A., OSBORNE, T., ROSE, N. (orgs.). "Foucault and political reason: Liberalism, neo-liberalism and rationalities of government". Londres: University College, 1996. BECKER, G. Investment in human capital: a theoretical analysis. Journal of Political Economy, Vol. 70 (5), parte 2, outubro de 1962, pp. 9-49. 
BERRY, D. "Digital Humanities: Knowledge and Critique in a Digital Age". Cambridge: Polity Press, 2017.

BONNAFOUS-BOUCHER, M. "Un libéralisme sans liberté. Du terme 'libéralisme' dans la pensée de Michel Foucault". Paris: L'Harmattan, 2001.

BOTERO, G. "Della ragioni di Estato". Venezia: Gioliti, 1589. [Online]. Disponível em: http://sciencepoparis8.hautetfort.com/media/02/01/1597175066.pdf (Acessado em 23 de março de 2019).

BURCHELL, G., GORDON, C., MILLER, P. (orgs.). "The Foucault effect: Studies in Governmentality”. Londres: Harvester Wheatsheaf, 1991.

CATROGA, F. "Entre Deuses e Césares: secularização, laicidade e religião civil: uma perspectiva histórica". Coimbra: Almedina, 2006.

DEBORD, G. "La Société du Spectacle". 3e édition. Paris: Les Classiques des Sciences Sociales, 1992.

DICKINSON, C. "A glória como arcano central do poder e os vínculos entre oikonomia, governo e gestão”. Cadernos Teologia Pública IHU, Ano XIV, Vol. 14, Nr. 127, 2017. DIEBEL-FISCHER, H. "Research Ethics in the Digital Age: Fundamentals and Problems". In: DOBRICK, F. M. et al. (orgs.). Research Ethics in the/digital Age. Wiesbaden: Springer, 2018. pp. 8-19.

."Research Ethics in the Digital Age: Fundamentals and Problems". In: DOBRICK, FM. et al. (orgs.) Research Ethics in the/digital Age. Wiesbaden: Springer, 2018.

DIONISIO AREOPAGITA. "Hierarquia celeste". São Paulo: Polar, 2015.

EDELMAN, E., MURGEL, J. "Biopolitical Economies in Higher Education Debt Formation: Financial Exploitation of Knowledge Production". 2013. [Online]. Disponível em: https://www.academia.edu/9059009/Biopolitical_Economies_in_Higher_Education Debt Formation. Acessado em 20 de fevereiro de 2019.

FOUCAULT, M. “'Omnes et singulatim': vers une critique de la raison politique”. In: Dits et Écrits. 1954-1988. Vol. IV. Paris: Gallimard, 1994.

"M. Foucault étudie la raison d'État". In: Dits et écrits, T. IV, 1980.

"Naissance de la biopolitique". Paris: Gallimard, 2004.

"Segurança, Território e população". São Paulo: Martin Fontes, 2008.

GAUTHIER, C. "À propos du gouvernement des conduites chez Foucault quelques pistes de lecture". In: CHEVALIER, J. (org.). La Gouvernabilité. Paris: CURAPP/ PUF, 1996. pp. 19-33.

GIGNAC, A. "Mistérios da economia (divina)e do ministério (engélico)". Cadernos IHU Ideias, São Leopoldo, Vol. 17, Nr. 280, 2019.

HOBBES, T. "Behemoth or the Long Parliament". Chicago: University Chicago Press, 1990.

KANTOROWICZ, E. "Os dois corpos do rei: um estudo de teologia política medieval”. São Paulo: Companhia das Letras, 1998.

KOTSKO, A. "Genealogy and Political Theology. On Method in Agamben's the Kingdom and the Glory". Political Theology, Vol. 14, 2014, pp. 107-114. 
LA MOTHE LE VAYER, F. de. (1756). L'Oeconomique du Prince. In: F. DE. LA MOTHE LE VAYER, Oeuvres de François de La Mothe Le Vayer. Nouvelle Edition Revue et Augmentée. Tomo I, parte II. Dresde, Michel Groell, pp. 285-298. [Online]. Disponível em https://gallica.bnf.fr/ark:/12148/bpt6k50693g.r=F.\%20de.\%20LA\%20 MOTHE\%20LE\%20VAYER\%2C\%20Oeuvres\%20de\%20Fran\%C3\%A7ois\%20de\%20 La\%20Mothe\%20Le\%20Vayer.?rk=21459;2 (Acessado em 23 de março de 2019). LA PERRIÈRE, G. "Le Miroir politique, oeuvre non moins utile que nécessaire à tous monarches, roys, princes, seigneurs, magistrats, et autres surintendants et gouverneurs de Republicques". $2^{\mathrm{a}}$ ed. Paris: V. Norment, 1567. 126 p. [Online]. Disponível em https://gallica.bnf.fr/ark:/12148/bpt6k114474p.r=LA\%20PERRI\%C3\%88RE\%2C\%20 G.?rk=42918;4\# (Acessado em 22 de março de 2019).

LASCOUMES, P. "La Gouvernementalité: de la critique de l'État aux technologies du pouvoir". Le Portique, 13-14, 2004 [Online]. Disponível em: https://journals.openedition. org/leportique/625 (Acessado em 21 de março de 2019).

LEMKE, T. "Foucault, governamentalidade e crítica". Tradução de M. A. Marino e E. A. C. Santos. São Paulo: Filosófica Politeia, 2017.

LEMM, V; VATTER, M. "The Government of Life. Foucault, biopolitics and neoliberalism". New York: Fordham University Press, 2014.

LÓPEZ, D. "Derecho, soberanía y biopolítica en Giorgio Agamben: eslabones indiferenciados de una misma "cinta de Moebius"'. Quaestio Iuris, Rio de Janeiro, Vol. 09, Nr. 02, 2016.

LUDUEÑA ROMANDINI, F. “Capitalismo y secularización”. Filosofia Unisinos, 12, maio-agosto/2011, pp. 99-113.

MCGOVERN, M. "The Dilemma of Democracy: Collusion and the State of Exception". Studies in Social Justice, Vol. 5, Issue 2, 2011, pp. 213-230.

MISES, L. "Human Action: a treatise on economics". Alabama: The Ludwig von Mises Institute Auburn, 1998.

PRIMERA, G. "Economic Theology, Governance and Neoliberalim: Lessons of the Kindong and Glory". Praktyka Teoretyczna, 3(17), 2015 [Online]. Disponível em: file://C:/Users/User/Downloads/5414-10579-1-SM\%20(1).pdf (Acessado em 29 de março de 2019).

RIVOLTELLA, P. C. "Digital Literacy: Tools and Methodologies for Information Society". Hershey: IGI Publishing, 2008.

ROSS, D. "Democracy, Authority, Narcissism: From Agamben to Stiegler". Contretemps, Vol. 6, January 2006, pp. 74-85.

SADIN, E. "La vie algorithmique. Critique de la raison numérique". Paris: L'Échappée, 2015.

SCHMITT, C. "Democracia e liberalismo: referendum e iniziativa popolare". Milão: Giuffré, 2001.

. "Versfassungslehre". Berlin: Dunker \& Humbolt, 1938.

SENELLART, M. "Les Arts de Gouverner. Du Regimen médiéval au concept de gouvernement”. Paris: Seuil, 1995. 
. "Michel Foucault: Governamentalità e ragion di Stato" [Online]. Disponível em: www.unina.it/ars/senellart.html (Acessado em 20 de março de 2019).

TOMÁS DE AQUINO. "De gubernatione mundi". In: . Summa Teologica. Madri: BAC, 2001.

TOSCANO, A. "Divine Management: Critical Remarks on Giorgio Agamben's The Kingdom and the Glory". Angelaki: Journal of the Theoretical Humanities, Vol. 16, Nr. 3, 2011, pp. 125-136. 